\title{
Physical characteristics of functional biscuits enriched in einkorn flakes
}

\section{Ivan Dimov' ${ }^{1}$, Viktorija Stamatovska ${ }^{2}$}

\author{
1 - Trakia University, Stara Zagora, Bulgaria \\ 2 - St. Kliment Ohridski" University of Bitola, Macedonia
}

Keywords:

Einkorn

Flaking

Functional

Biscuits

Article history:

Received

29.01.2018

Received in revised form 26.05.2018

Accepted

29.06.2018

\section{Corresponding}

author:

Ivan Dimov

E-mail:

ivendi_81@

abv.bg

\section{Abstract}

Introduction. The modern tendencies related to the consumption of functional food suggest that the einkorn is a cereal which can play an important role in human nutrition.

Materials and methods. The following basic materials were used for the production of biscuits: whole grain einkorn (Triticum monoccocum L.) flour and einkorn flakes. The manufacturing of the biscuits, as well as the determination of their physical properties (baking loss and volume) was carried out according to AACC Method 10-50D. Biscuits color was determined by spectral method using tintometer produced by Lovibont Tintometer RT 100 Colour in the CIE Lab system.

Results and discussion. During the baking, water present in the formed dough evaporates which gives biscuits of characteristic structure. The greatest baking losses showed the biscuits made from $100 \%$ einkorn flour $(15.16 \pm 1.01 \%)$ and the smallest - these made from $100 \%$ einkorn flakes $(9.54 \pm 1.22 \%)$, with the diference beteen the two samples being $5.62 \%$.

The results obtained for the baking losses of the biscuits made from $100 \%$ flakes produced are statistically significant $(\mathrm{p}<0.05)$.

The data on the volume of the biscuits produced show that the largest volume had the biscuits made from $100 \%$ einkorn flour $\left(79.00 \pm 0.50 \mathrm{~cm}^{3}\right)$.

All the samples of biscuits had colors in the green and yellow spectrum and the lightest ones were these produced from $100 \%$ einkorn flakes.

The differences between the individual samples were insignificant.

Conclusions. The increase of the amount of einkorn flakes added to einkorn flour results in slightly lower baking losses and volume of baked biscuits, and a lights biscuits color.

\section{DOI:}




\section{Introduction}

The modern tendencies related to the consumption of functional food suggest that the einkorn is a cereal which can play an important role in human nutrition. This is especially true by the development of new specialized nutritional products of higher quality with respect to their nutritional value. In modern world, the food we consume must, besides providing the necessary energy and nutrients, also have positive effect on human health [1].

Consumer interest in healthy eating is targeted on certain foods and food ingredients $[2]$.

Einkorn was domesticated more than 10000 years ago, most probably in the Karakadak mountains in southeastern Turkey and its cultivation spread to Europe during the agricultural revolution. Nowadays, einkorn is grown in the mountain regions of the mediterranian (Turkey, Balkan countries, southern Italy, southern France, Spain and Morocco). Recently, the tendency toward development of sustainable agriculture has elad to increased attention to the nutritious aspects of food. This resulted in rediscovery of some forgotten cultures like einkorn. Despite the low yield (about trice less than bread wheat), Regardless of its low yields (about a third from the bread wheat), there has been significant recovery of the cultivation of this kind of wheat in some countries (France, Germany, Austria, Hungary, Bulgaria and Italy) [3].

Einkorn (Triticum monococcum L. ssp. monococcum) is a diploid species $(2 n=2 x=14$ chromosomes) of hulled wheat and it is close relative of durum wheat. Recent studies highlight its good nutritional qualities when consumed by humans [4,5].

Lately, the flaked products are more and more widely used. They are contained in many food products used as snacks. They are used as supplement in bread, bakery and confectionery, including the production of biscuits [6].

The process of preparation of flaked products is as follows:

1. Cleaning and sorting - before the processing, cereals are cleaned and sorted. Cleaning removes unwanted ingredients like grain from other crops, pebbles, sand, etc. simultaneously, the grains are sorted according to their quality. The shriveled, broken and unripe grains are removed by blowing with hot air.

2. Hulling - the aim is to remove the hull of the grains and obtain dehulled ones. This is done by rolling between rubber belts (rolls) so the hull is removed without damaging the kernel. The kernels are then blown with air to remove the remaining hulls.

3. Brushing - the dehulled grains are the brushed with brushes.

4. Heating - the grains are heated to $100^{\circ} \mathrm{C}$ in special furnaces. By $\mathrm{t}$ his operation, the surface moisture increases and condenses. The vapor obtained deactivates the enzymes contained in the grains. The starch turns to paste.

5. Drying and fractionation - drying is carried out in special desiccators where the moisture content in the grains decreases and they can now be stored. The, the grains are separated into two fractions according to their size.

6. Rolling - by this process, flakes of various sizes are obtained by pressing the grains between rolls. The process of rolling involves the use of water vapor which softens the grains.

7. Drying and packing -the flaked products should be dried before packing until moisture content in them remains ca. $11 \%$; then they are packed in suitable packings [7].

Biscuits are bakery products which most often are made from flour, fats and sugar. Various types of biscuits are offered on the market but today, when people wish to eat healthy food, it is necessary to produce "functional" biscuits [8]. 
It is considered that biscuit production accounts for an important part of the food industry production in most countries around the world. They have great nutritional value, especially when the raw materials used for their production are rich in fats and proteins [9]. Their important role and importance can be attributed to at least four key factors: Тяхното важно място и значение, може да се дължи най-малко на четири ключови фактора:relatively long shelf life; great variety; human desire and predisposition to sugar and chocolate, as well as their comparatively low price [10].

The aim of the present paper is to study the effect of flaked einkorn (Triticum monococcum L.) on some physical properties in biscuits produced from whole grain einkorn flour (base flour) to which einkorn flakes are added in quantities 30\%, 50\%, 70\%and 100\%at the expense of the base flour.

\section{Materials and methods}

\section{Materials}

The following materials were used for the production of biscuits: whole grain einkorn (Triticum monoccocum L.) flour and flaked einkorn produced in the Plovdiv region, saccharose and glucose in the form of glucose solution (as sweeteners), cow butter, sodium bicarbonate and cooking salt - purchased from the market, drinking water from the public water supply network complying with the requirements of Regulation № 9 [11].

\section{Methods}

\section{Production of biscuits}

The manufacturing of the biscuits, as well as the determination of their physical properties (baking loss and volume) was carried out according to AACC Method 10-50D [12].

\section{Colours of biscuits}

Biscuits color was determined by spectral method using tintometer produced by Lovibont Tintometer RT 100 Colour in the CIE Lab system. The average of several measurements was taken. The general change of color was calculated by formula (1) [13].

$$
\Delta E=\sqrt{\left(L-L_{0}\right)^{2}+\left(b-b_{0}\right)^{2}+\left(a-a_{0}\right)^{2}}
$$

where: the indicators with index 0 refer to the baked biscuits and the other ones - to the raw dough.

The parameter $\Delta \mathrm{E}$ shows the relationship between the human perception of biscuit color and the total change of color (Table 1). 
Table 1

Relationship between the human perception of biscuit color and the total change of color $(\Delta \mathrm{E})$

[14]

\begin{tabular}{|l|c|}
\hline \multicolumn{1}{|c|}{ Human perception } & $(\Delta \mathbf{E})$ \\
\hline No great difference & $<2$ \\
\hline Very small perceptible difference & $0.2 \div 1$ \\
\hline Small perceptible difference & $1 \div 3$ \\
\hline Medium perceptible differences & $3 \div 6$ \\
\hline Great perceptible differences & $>6$ \\
\hline
\end{tabular}

\section{Statistical analysis}

The results obtained from the analyses are presented in tables and figures and their statistical processing was performed using XL Stat and Microsoft Excel 2013. In the XL Stat software, the analysis of the main factors (Main effects ANOVA) was employed, as well as the Fisher criterion for the least statistically significant differences (LSD) at significance factor of $95 \%(\mathrm{p}<0.05)$.

\section{Results and discussion}

The innovations in the production of biscuit applied in the recent decade are oriented to the making of biscuits with reduced content of sugars, substitution of sugars with sweeteners, use of fats of different properties, as well as enrichment of the biscuits with additives with functional properties [8]. Table 2 shows some physical characteristics (baking loss and volume) of the biscuits manufactured.

Table 2

Physical characteristics of biscuits

\begin{tabular}{|c|c|c|}
\hline Biscuits/Properties & Baking loss (\%) & Volume $\left.\mathbf{( c m}^{\mathbf{3}}\right)$ \\
\hline $100 \% \mathrm{E}$ & $15.16 \pm 1.01^{\mathrm{a}}$ & $79.00 \pm 0.50^{\mathrm{a}}$ \\
\hline $70 \% \mathrm{E}+30 \% \mathrm{EF}$ & $14.10 \pm 0.52^{\mathrm{a}}$ & $53.00 \pm 1.48^{\mathrm{b}}$ \\
\hline $50 \% \mathrm{E}+50 \% \mathrm{EF}$ & $12.98 \pm 0.63^{\mathrm{b}}$ & $52.93 \pm 1.33^{\mathrm{b}}$ \\
\hline $30 \% \mathrm{E}+70 \% \mathrm{EF}$ & $13.03 \pm 0.96^{\mathrm{ab}}$ & $52.33 \pm 1.27^{\mathrm{b}}$ \\
\hline $100 \% \mathrm{EF}$ & $9.54 \pm 1.22^{\mathrm{b}}$ & $51.33 \pm 1.53^{\mathrm{b}}$ \\
\hline
\end{tabular}

${ }^{*} E$ - einkorn flour; EF - einkorn flakes. **The data presented are the average of 5 consecutive measurements \pm the standard deviation. ***Values in the same column with different exponents $(a-b)$ have statistically significant difference $(p<0.05)$ ANOVA, Fisher s LSD. 
During the baking, water present in the formed dough evaporates which gives biscuits of characteristic structure $[14,15]$. It can be seen from Table 2 that the greatest baking losses showed the biscuits made from $100 \% \mathrm{E}(15.16 \pm 1.01 \%)$ and the smallest - these made from $100 \% \mathrm{EF}(9.54 \pm 1.22 \%)$, with the diference beteen the two samples being 5,62\%. I.e., the use of $\mathrm{EF}$ for production of biscuits results in decrease of the losses by the baking of the final product. It was found also for the samples made from combination of flour and flakes that the baking losses decrease insignificantly with the increase of einkorn flakes content in biscuit composition. One exception from the general tendency are the biscuits containing $70 \% \mathrm{EF}$ but the difference compared to the previous sample $(50 \% \mathrm{EF})$ is quite small and within the standard deviation. The results obtained for the baking losses of the biscuits made from $100 \% \mathrm{EF}$ are statistically significant $(\mathrm{p}<0.05)$.

The data on the volume of the biscuits produced (Table 2) show that the largest volume had the biscuits made from $100 \%$ einkorn flour $\left(79.00 \pm 0.50 \mathrm{~cm}^{3}\right)$. These data are statistically significant compared to the others $(\mathrm{p}<0.05)$. it was established also that even with the smallest amount of einkorn flakes added (30\%), the volume of the biscuits manufactured significantly decreases compared to these made from $100 \%$ einkorn flour (the volume decreased by 26 $\mathrm{cm}^{3}$ ). The increase of the einkorn flakes content above 30\% resulted in insignificant decrease of biscuit volume.

The values of bisuits color measured by the CIE L*a*b* system are presented in Table 3.

Colour of biscuits measurend with CIE Lab system

Table 2

\begin{tabular}{|c|c|c|c|c|}
\hline Biscuits/Parameter & $\mathbf{L} *$ & $\mathbf{a}^{*}$ & $\mathbf{b}^{*}$ & $\Delta \mathbf{E}$ \\
\hline $100 \% \mathrm{E}$ & $49.81 \pm 1.82$ & $2.79 \pm 1.75$ & $22.53 \pm 2.92$ & $6.02 \pm 0.02$ \\
\hline $70 \% \mathrm{E}+30 \% \mathrm{EF}$ & $48.47 \pm 0.21$ & $4.34 \pm 1.83$ & $23.54 \pm 2.42$ & $5.44 \pm 2.32$ \\
\hline $50 \% \mathrm{E}+50 \% \mathrm{EF}$ & $48.48 \pm 1.28$ & $2.86 \pm 1.80$ & $21.60 \pm 3.17$ & $5.00 \pm 2.22$ \\
\hline $30 \% \mathrm{E}+70 \% \mathrm{EF}$ & $48.49 \pm 1.52$ & $4.86 \pm 0.97$ & $23.99 \pm 1.55$ & $4.85 \pm 2.18$ \\
\hline $100 \% \mathrm{EF}$ & $54.01 \pm 2.11$ & $3.03 \pm 0.04$ & $20.61 \pm 0.06$ & $4.23 \pm 1.40$ \\
\hline
\end{tabular}

*E-einkorn flour; EF-einkorn flakes. **the data presented are the average of 5 consecutive measurements \pm standard deviation

The parameter $\mathbf{L}^{*}$ show the lightness of the color. The closer its value is to zero, the darker is the color of the object studied. If the value of this parameter is close to 100 , then the object studied looks brighter [16]. As can be seen from Table 3, the values of color of the biscuits produced from mixture of $\mathrm{E}+\mathrm{EF}$ were almost the same but lower than these for the samples made from $100 \%$ einkorn and $100 \%$ einkorn flakes, i.e. the latter appear lighter. The highest values of this parameter had the biscuits made from $100 \% \mathrm{EF}(54.01 \pm 2.11)$, i.e. they were the lightest while the lowest values sjowed the biscuits produced from $30 \% \mathrm{E}$ and $70 \% \mathrm{EF}(48.49 \pm 1.52)$, i.e. they were the darkest.

The value of the parameter $\mathbf{a}^{*}$ in the CIE $\mathrm{L}^{*} \mathrm{a}^{*} \mathrm{~b}^{*}$ system define whether the color of the object studied is red or green. If the value of this parameter is positive then the color of the object studied is green, if they are negative, then the color of the biscuits is red [16]. It can be seen from the Table that the highest value of this parameter had the biscuits made 
from $30 \% \mathrm{E}$ and $70 \% \mathrm{EF}(4.86 \pm 0.97)$ and the lowest value - these made from $100 \% \mathrm{E}$ $(2.79 \pm 1.75)$ but the differences are quite small. Obviously, all the samples studied had green color.

The value of the parameter $\mathbf{b}^{*}$ show whether the color of the object studied is blue of yellow. If the value is negative, then the object studied is blue and if positive, its color is yellow [16]. It can be seen from the results shown in Table 3 that the highest value of $\mathbf{b}^{*}$ had the biscuits made from $30 \% \mathrm{E}$ and $70 \% \mathrm{EF}(23.99 \pm 1.55)$ and the lowest value had the biscuits made from $100 \% \mathrm{EF}(20.61 \pm 0.06)$. the differences are very small. With respect of this parameter, the biscuits obviously had yellow color.

The parameter $\mathbf{\Delta} \mathbf{E}$ shows the relationship between the human perception of biscuits color and the total change of the color. As can be seen from Table 3, the values of this parameter decrease with the increase of the amount of EF in the biscuits.

The values determined, considered with respect to the definitions in Table 1, indicate that all type of biscuits can be classified in the group "medium perceptible differences" of biscuits color, even these produced from $100 \%$ einkorn, since it was assumed that their value of $\Delta \mathrm{E}=6.02$ exceeds the boundary value $(\Delta \mathrm{E}=3-6)$ and this difference is within the range of the standard deviation.

\section{Conclusion}

It was concluded from the studies carried out that the increase of the amount of einkorn flakes added to einkorn flour results in slightly lower baking losses and volume of baked biscuits. The highest volume had the biscuits without einkorn flakes $(100 \% \mathrm{E})$. substantial decrease of biscuits volume was observed even with the addition of the smallest quantity of einkorn flakes (30\%) to the recipe. The baking losses are significantly smaller (by about $3,5 \%$ ) for the biscuits manufactured from $100 \% \mathrm{EF}$ compared to the other samples where the difference was only $1 \%$.

All the samples of biscuits had colors in the green and yellow spectrum and the lightest ones were these produced from $100 \%$ einkorn flakes. The differences between the individual amples were insignificant.

\section{References}

1. Komolka P., Górecka, D., Szymandera-Buszka K., Jędrusek-Golińska A., Dziedzic K. Waszkowiak K. (2016), Sensory qualities of pastry products enriched with dietary fi ber and polyphenolic substances, Acta Sci. Pol. Technol. Aliment., 15(2), pp.161-170.

2. European Commission (2010), Functional Food, Directorate-General for Research, http://www.eurosfaire.prd.fr/7pc/documents/1276590504_functional_foods_en_publi_ ce.pdf.

3. Hidalgo A., Brandolini A. (2013), Nutritional Properties of einkorn wheat (Triticum monococcum L.), Journal of the Science of Food and Agriculture, 94(4), pp. 601-612.

4. Hidalgo A., Brandolini A. (2008), Protein, ash, lutein and tocols distribution in einkorn (Triticum mono coccum L. subsp. Monoccum) seed Fractions, Food Chemistry, 107(1), pp. 444-448.

5. Nakov Gj., Stamatovska V., Necinova Lj., Ivanova N., Damyanova S. (2016), Nutritional properties of einkorn wheat (Triticum monococcum L.). Proceeding of 55th Science Conference of Ruse University, pp. 381-384. 
6. Goudar G. Sathisha G.J. (2016), Effect of extrusion and flaking on the retention of nutrients and phenolic compounds in millet grains, International Journal of Food Science and Nutrition, 1(4), pp. 08-11.

7. Božjakovina PJ BIVITA (2017), HACCP Studija, Dijagrami tijeka, Hrvatska.

8. Nakov Gj. Stamatovska V., Ivanova N., Damyanova S., Godjevargova Tz., Koceva Komlenić D. (2018), Psysicochemical characteristics of functional biscuits and In vivo determination of glucose in blood after consumption of functional biscuits, Journal of Hygienic Engineering and Design, 22, pp. 25-32.

9. Sulieman E., Mohammed A., Elkhalifa E. (2008), Evaluation of the chemical and sensory characteristics of biscuits supplemented with soybean flour, Gezira Journal of Agricultural Science, 6(1), pp. 97-107.

10. Manley D. (2000), Technology of biscuits, cracker and cookers, Woodhead Publishing Limited, Cambridge.

11. Regulation № 9 from March 16, 2001 of the quality of the water intended for drinking and household purposes.

12. AACC Method 10-50D (2000), Baking Quality of Cookie Flour, Approved Method of the American Association of Cereal Chemists, 10th ed. AACC, ST. Paul.

13. Budžaki, S., Koceva, Komlenić, D., Lukinac, Čačić, J., Čačić, F., Jukić, M. \& Kožul, Ž. (2014), Influence of cookies composition on temperature profiles and qualitative parameters during baking, Croat. J. Food Sci. Technol., 6(2), pp. 72-78.

14. Nakov, Gj., Koceva, Komlenić, D., Stamatovska, V., Jukić M. (2017), Influence on time of baking and different role of barley flour on the colour of the biscuits, Journal of Hygienic Engineering and Desing, 21, pp. 90-95.

15. Nakov Gj. (2017), Physucal Characteristics of Functional Biscuits, Proceedings of University of Ruse, 56(10.2), pp.125-129.

16. Konica Minolta, Available at: https://sensing.konicaminolta.us/blog/identifying-colordifferences-using-l-a-b-or-1-c-h-coordinates 